\title{
Análise quantitativa e espacial de distribuição dos períodos de chuva intensa e seca na Bacia Hidrográfica do rio Paraíba do Sul
}

\author{
Suzana Maria Inacio de Carvalho ${ }^{(1)}$, Thiago França Shoegima ${ }^{(2)}$ Jonas Teixeira Nery ${ }^{(3)}$ \\ (1) Universidade Estadual Paulista "Júlio de Mesquita Filho", suzana-carvalho@live.com \\ (2) Universidade Estadual Paulista "Júlio de Mesquita Filho", thiago.shoegima@gmail.com \\ (3) Universidade Estadual Paulista “Júlio de Mesquita Filho”, jonas@ ourinhos.unesp.br
}

Eixo: Climatologia em diferentes níveis escalres: Mudanças e variabilidades

\begin{abstract}
Resumo
A bacia hidrográfica do rio Paraíba do Sul está situada em uma região de grande desenvolvimento econômico, entre os estados São Paulo, Minas Gerais e Rio de Janeiro. Inserida em um dos ecossistemas mais degradados do Brasil, a Mata Atlântica, torna-se uma região de grande importância em estudos para sua coservação. O clima, sendo um ator fundamental na dinâmica de processos hidrológicos, como ecológicos, é estudado através dos índices SPI (Standardized Precipitation Index) e RAI (Rainfall Anomaly Index), dos quais permitem avaliar a variabilidade da precipitação, quantificando o déficit da precipitação em múltiplas escalas de tempo que refletem o impacto da seca na disponibilidade de fontes de água, sendo uma valiosa ferramenta para a análise climatológica de períodos de secas ou chuvas intensas. Este trabalho teve como objetivo avaliar de forma quantitativa e espacial os períodos de chuva intensa e seca na Bacia Hidrográfica do rio Paraíba do Sul fazendo-se uso de tais índices. Os resultados demonstraram-se satisfatórios, demonstrando que a região Nordeste, por exemplo, foi a que apresentou maior amplitude em relação aos índices, tanto para os períodos de chuva como de seca, sendo uma região que merece grande atenção por parte do poder público com medidas a serem adotadas antes, durante e depois de ocorrências por eventos adversos de estiagem e alta pluviosidade.
\end{abstract}

Palavras chave: Climatologia, variabilidade,precipitação, seca, Bacia Hidrográfica do rio Paraíba do Sul.

\section{Introdução}

$\mathrm{Na}$ região tropical como na Mata Atlântica, a sazonalidade climática, especialmente da precipitação, tem fortes influências no meio e variações sazonais significativas. Na década de setenta, episódios de secas como consequência das alterações climáticas, em várias regiões do globo terrestre, evidenciou a vulnerabilidade do homem a esse risco climático, demonstrando a necessidade de melhor entendimento, previsão de ocorrência e uso correto de medidas mitigatórias. Alguns eventos meteorológicos, como a seca, e o excesso de chuva, são de extrema importância devido a seus impactos no sistema hidrológico, ecológico e socioeconômico. 
Muitos estudos sobre mudanças climáticas têm demonstrado uma certa polarização da ocorrência das chuvas para diferentes regiões do planeta, tendendo ao aumento da ocorrência de chuvas intensas e da severidade das secas meteorológicas (Marengo et al., 2010).

$\mathrm{Na}$ climatologia, o uso de índices são de grande importância, possibilitando conhecer a distribuição dos eventos nas diferentes regiões de estudo, na qual a influência do ciclo hidrológico tem papel fundamental.

Índices meteorológicos como SPI (Standardized Precipitation Index), auxiliam na quantificação do déficit de precipitação para múltiplas escalas de tempo que refletem o impacto da seca na disponibilidade de fontes de água, sendo uma valiosa ferramenta para a análise climatológica de períodos de secas ou chuvas intensas (Lloyd-Hughes e Saunders, 2002). Em relação ao índice RAI (Rainfall Anomaly Index), desenvolvido por Rooy (1965), este incorpora um procedimento de classificação para ordenar magnitudes de anomalias de precipitações positivas e negativas.

Partindo para o campo da análise da variabilidade climática, esta se reveste de importância quando analisamos os impactos do clima em áreas de interesse socioeconômico e ambiental, como, por exemplo, a prática inadequada de utilização do solo em bacias rurais, a partir da remoção da cobertura vegetal nativa para inserção de pastagens ou outras culturas exóticas. É através destes tipos de análises que se torna possível conhecer os problemas e processos de ordem climática atuantes na região e ao mesmo tempo buscas de soluções ou a minimização destes por meio de planejamento de ações (Silva et al., 2010; Souza et al., 2013)

Uma área de grande interesse, ainda pouco investigada, é a Mata Atlântica Paulista, inserida na bacia hidrográfica do Paraíba do Sul, cujo bioma original (Mata Atlântica) tem sido suprimido e substituído por pastagens, cultivos agrícolas e práticas silvicultoras. Este bioma apresenta peculiaridades quanto ao funcionamento ecofisiológico imposto pela variação do clima regional, bem como relacionadas às variações na latitude, longitude e altitude.

Poucos estudos abordam a influência da variabilidade climática desta região. Neste contexto, na situação atual em que a Mata Atlântica se encontra cada vez mais fragmentada e perdendo informações sobre a dinâmica do seu sistema natural, estudos mais aprofundados relacionados a aplicação de índices meteorológicos, principalmente em relação a precipitação são de suma importância para avaliar a situação da referida bacia em relação a dinâmica de fenômenos 


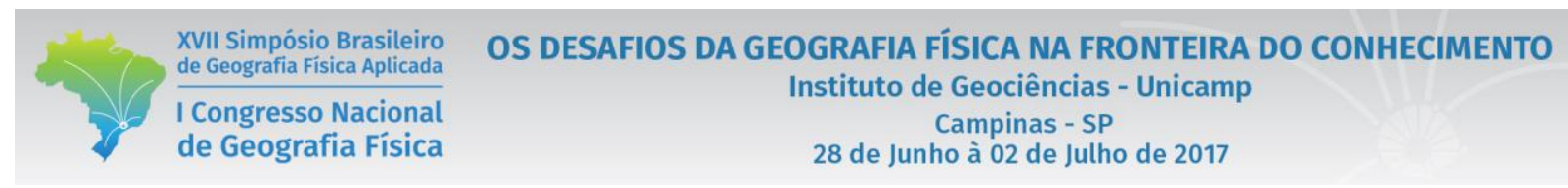

pluviográficos, e consequentemente os eventuais impactos destes no restante do sistema (hidrológico, vegetal e antrópico).

Para investigar esta questão, este trabalho irá utilizar dois índices meteorológicos SPI e RAI aplicando os dados da série histórica de chuvas do banco de dados da Agência Nacional de Águas (ANA) para o período de 1970 a 2010.

\section{Materiais e Métodos}

\section{1 Área de Estudo}

A região de estudo compreende a Unidade de Gerenciamento dos Recursos Hídricos do Paraíba do Sul (UGRHI-02), Figura 1.

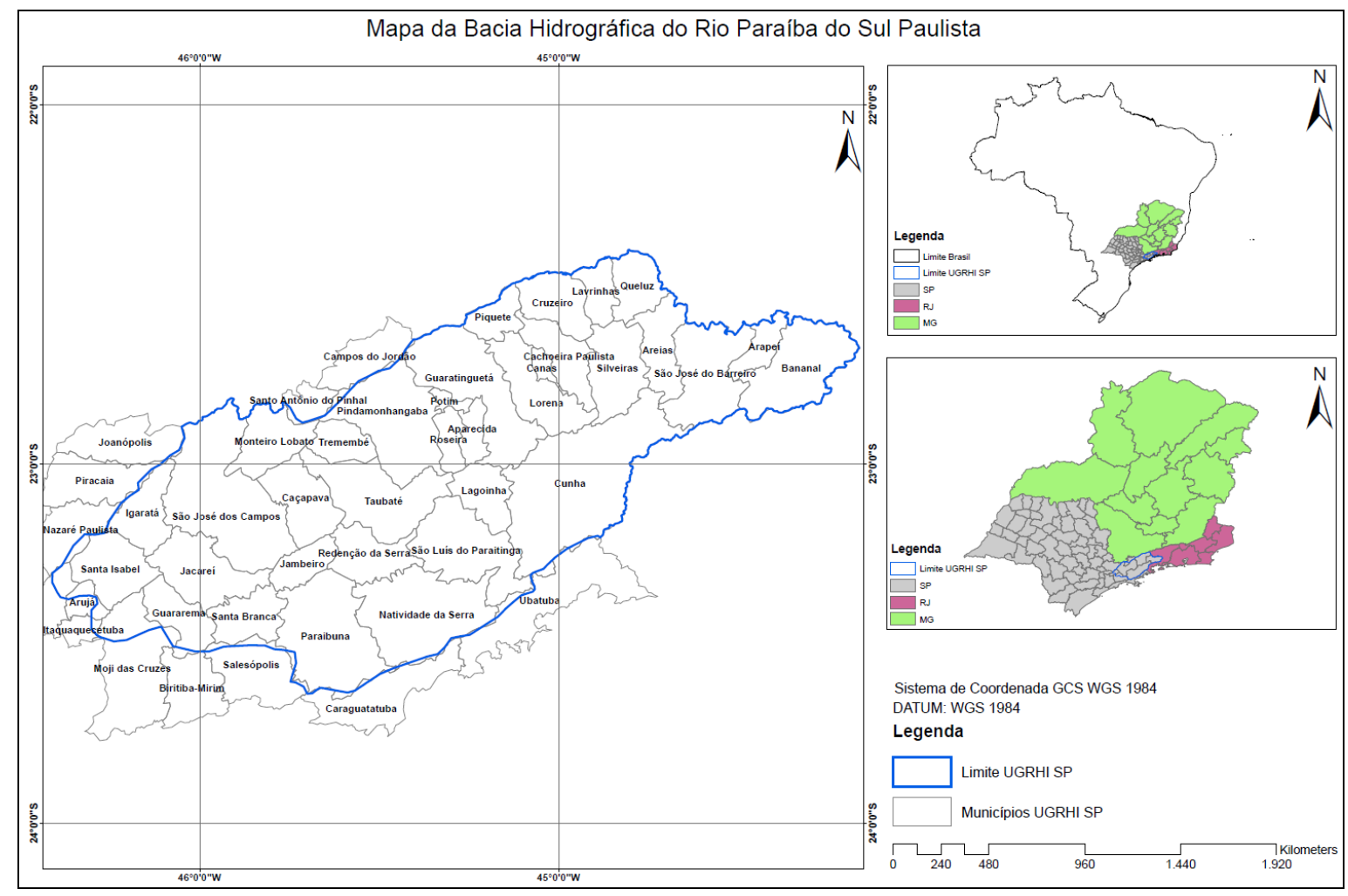

Figura 1 - Localização da área de estudo.

A região é compreendida entre as duas maiores metrópoles da região sudeste, São Paulo e Rio de Janeiro, na mesma também está localizado um dos polos tecnológicos e industriais mais importantes do Brasil. 
O clima da referida UGRHI é caracterizado como subtropical quente, com temperatura média anual oscilando entre $18^{\circ} \mathrm{C}$ e $24^{\circ} \mathrm{C}$. As máximas precipitações ocorrem nas cabeceiras mineiras da bacia e nos pontos mais altos das serras do Mar e Mantiqueira, chegando a valores de 2.250 $\mathrm{mm} / \mathrm{ano}$. O período de verão é caracterizado como chuvoso com precipitação acumulada entre 200 e $250 \mathrm{~mm} /$ mês nos meses com máxima precipitação (dezembro e janeiro). No inverno, o intervalo entre os meses de maio a agosto corresponde ao período mais seco, com precipitação acumulada inferior a $50 \mathrm{~mm} / \mathrm{mês}$ (Marengo e Alves 2005).

\subsection{Materiais}

Para avaliar a variabilidade da precipitação, foram utilizadas 16 estações meteorológicas da Agências Nacional das Águas (ANA), os dados das referidas estações foram obtidos através do site HIDROWEB para um período de 1970 a 2010 na região de estudo.

Para o tratamento dos dados pluviométricos foram utilizados os softwares Excel para tabulação, organização e geração de gráficos, e o software estatístico $\mathrm{R}$ para o tratamento estatístico e aplicação dos índices RAI e SPI sobre a série histórica de dados de chuva para a referida região. Os resultados obtidos foram especializados nos softwares de geoprocessamento SURFER v.12 e ArcGIS v.10.2, o método de interpolação foi o de Krigagem.

\subsection{Método}

Para este trabalho, foi utilizada uma série histórica de dados diários das variáveis climáticas, precipitação pluvial coletados em 32 estações meteorológicas, contudo, das 32 estações apenas 16 estações foram escolhidas para serem analisadas, as demais foram descartadas devido a problemas de falhas em períodos de medições ou ausência de dados em alguns anos, logo optouse em trabalhar apenas com as estações que apresentavam medições de forma continua e dentro do período escolhido de análise.

Segundo Marengo (2008, p.83) a disponibilidade de água no Brasil tem grande dependência em relação aos fatores climáticos, ou seja, o ciclo anual das chuvas e as vazões no país tem variação entre as bacias, e de fato a variabilidade interanual do clima, que associada aos eventos de El Ninõ, ou a variabilidade na tempertaura da superfície do mar, podem acarretar o desenvolvimento de anomalias climáticas, estas anomalias dependendo do tipo de evento e período de ocorrência 
podem acarretar situações de eventos extremos, seja em relação a chuvas ou a secas, cabe destacar que a intensidade de cada tipo de evento está diretamente relacionada ao contexto geográfico específico de cada região.

O monitoramento da ocorrência de eventos extremos (como seca e chuva intensa) tem sido realizado atraves de índices climáticos. A compreensão de eventos como seca, a qual refere-se a precipitação abaixo das normais esperadas e chuva intensa sendo a ocorrência da precipitação em um grande volume num curto espaço de tempo, são de extrema importância pois são eventos que impactam de forma significativa diversos setores, afetando não somente a economia, como também as dinâmicas naturais na região.

Em relação a escolha dos índices meteorológicos, foi escolhida a aplicação de dois índices como forma de comparação dos resultados obtidos por estes para a referida área de estudo, bem como avaliar o índice que melhor representa a situação da pluviosidade para esta área. Em relação aos índices os dois apresentam fácil aplicação e cálculos considerados simples, no qual os mesmos necessitam apenas da entrada de um tipo de dados, neste caso de precipitação pluvial (Guttman, 1998).

No presente trabalho, são apresentadas somente as equações principais para o cálculo dos índices SPI e RAI.

Em relação ao índice SPI, a distribuição gama com dois parâmetros e a sua função de probabilidade cumulativa (Thom, 1958), é a mais comumente usada para o cálculo.

O cálculo do SPI leva em consideração dados de precipitação pluvial ajustada por meio da distribuição gama e, posteriormente, transformada em uma distribuição normal que, por definição, apresenta sua média com valor zero e variância unitária (Wu et al., 2005). A equação:

$$
\mathrm{SPI}=\left\{ \pm \mathrm{t}-\left[\left(\mathrm{c}_{0}+\mathrm{c}_{1}+\mathrm{c}_{2} \mathrm{t}^{2}\right) /\left(1+\mathrm{d}_{1} \mathrm{t}+\mathrm{d}_{2} \mathrm{t}^{2}+\mathrm{d}_{3} \mathrm{t}^{3}\right)\right]\right\},
$$

Após aplicado o índice SPI, os valores/resultados obtidos são classificados conforme proposto por McKee (1993), sendo que os valores podem variar para os períodos de chuva fraca $(0,99)$ a chuva extrema $(>2,0)$, ou de Seca fraca $(-0,50$ a $>-2,0)$, sendo considerado como Normal os valores de $0,49 \mathrm{a}-0,49$, conforme disposto na tabela a seguir. 
Tabela I - Índices de classificação SPI

\begin{tabular}{|l|l|}
\hline \multicolumn{2}{|c|}{ Classificação do SPI } \\
\hline$\geq 2,00$ & Chuva extrema \\
\hline 1,99 a 1,50 & Chuva severa \\
\hline 1,49 a 1,00 & $\begin{array}{l}\text { Chuva } \\
\text { moderada }\end{array}$ \\
\hline 0,99 a 0,50 & Chuva fraca \\
\hline 0,49 a $-0,49$ & Normal \\
\hline$-0,50$ a $-0,99$ & Seca fraca \\
\hline$-1,00$ a $-1,49$ & Seca moderada \\
\hline$-1,50$ a,- 199 & Seca severa \\
\hline$\leq-2,00$ & Seca extrema \\
\hline
\end{tabular}

Fonte: Mckee et al., (1993).

Quanto ao índice RAI, este consiste simplesmente da determinação de anomalias extremas de precipitação. Os valores são obtidos segundo as equações (2) e (3) definidas por Rooy (1965).

$R A I=3\left[\frac{(N-K)}{(M-K)}\right] \quad$ Para anomalias positivas (2)

$R A I=-3\left[\frac{(N-K)}{(X-K)}\right] \quad$ Para anomalias negativas (3)

Em que: $\mathrm{N}$ é precipitação mensal atual; $\mathrm{K}$ a precipitação média mensal (mm); $\mathrm{M}$ a média das dez maiores precipitações mensais e $\mathrm{X}$ a média das dez menores precipitações mensais.

Seca e chuva intensa

\section{Resultados e Discussão}

Para a realização da análise estatística dos dados obtidos nas 16 estações escolhidas utilizou-se do software R para trabalhar os dados, especificamente sua extensão chamada Precinticon, extensão está desenvolvida para tratamento e análise de dados relacionados a climatologia, dentro da 
XVII Simpósio Brasileiro de Geografia Fisica Aplicada

I Congresso Nacional

de Geografia Física
OS DESAFIOS DA GEOGRAFIA FÍSICA NA FRONTEIRA DO CONHECIMENTO

Instituto de Geociências - Unicamp

Campinas - SP

28 de Junho à 02 de Julho de 2017

referida ferramenta utilizou-se as aplicações relativas aos índices RAI e SPI, no qual os resultados obtidos são apresentados a seguir na forma de Tabelas (II e III), Gráficos (Figuras 2 e 3) e Mapas (Figuras 4 a 5).

Tabela II - Resultados do índice SPI.

\begin{tabular}{|c|c|c|c|c|c|c|c|c|c|c|c|c|}
\hline Ano/Mês & JAN & FEV & MAR & ABR & MAI & JUN & JUL & AGO & SET & OUT & NOV & DEZ \\
\hline 1976 & & & $-0,12$ & 0,25 & 0,76 & 0,58 & 0,91 & 1,84 & 1,66 & 1,63 & 0,96 & 0,26 \\
\hline 1982 & 0,49 & 0,45 & 0,31 & 0,07 & $-1,14$ & 0,19 & 1,11 & 1,53 & $-0,24$ & $-0,11$ & 1,39 & 3,23 \\
\hline 1983 & 2,47 & 1,32 & 0,32 & 0,11 & 1,99 & 2,66 & 2,06 & 0,90 & 0,19 & 0,48 & 1,15 & 0,55 \\
\hline 1997 & 2,65 & 2,77 & 1,85 & $-0,83$ & $-1,25$ & 0,94 & 0,76 & 0,60 & $-1,13$ & 0,00 & 1,06 & 0,74 \\
\hline 1998 & $-0,27$ & $-0,27$ & 0,68 & 1,68 & 1,57 & 0,92 & $-0,28$ & $-0,20$ & 0,96 & 1,43 & 0,72 & 0,41 \\
\hline 2010 & 0,84 & 0,67 & 1,25 & 0,79 & 0,04 & $-0,92$ & $-1,36$ & $-1,33$ & $-0,41$ & $-0,06$ & $-0,61$ & $-1,07$ \\
\hline
\end{tabular}

Tabela III - Resultados do índice RAI.

\begin{tabular}{|c|c|c|c|c|c|c|c|c|c|c|c|c|}
\hline Ano/Mê & JAN & FEV & MAR & ABR & MAI & JUN & JUL & AGO & SET & OUT & NOV & DEZ \\
\hline 1976 & 0,27 & 0,51 & 0,30 & $-0,97$ & 0,58 & $-1,45$ & $-0,66$ & \begin{tabular}{|l|}
0,89 \\
\end{tabular} & \begin{tabular}{|l|}
0,45 \\
\end{tabular} & 0,40 & 0,36 & 0,34 \\
\hline 1982 & 0,54 & 1,31 & $-0,22$ & $-2,78$ & $-1,11$ & 0,72 & $-0,56$ & $-2,20$ & $-2,29$ & 0,64 & 2,07 & 3,61 \\
\hline 1983 & 1,42 & $-1,36$ & 0,90 & $-0,41$ & 1,72 & $\mid 1,18$ & $-2,86$ & $\mid-3,00$ & \begin{tabular}{|l|}
0,82 \\
\end{tabular} & 0,04 & 0,61 & 0,85 \\
\hline 1997 & $\mid 5,43$ & 0,47 & $-2,75$ & $-1,15$ & $-0,44$ & 0,70 & $-2,52$ & $-2,91$ & $-1,59$ & 0,77 & 1,20 & $-0,53$ \\
\hline 1998 & 0,19 & 1,40 & 0,83 & 0,91 & $-0,03$ & $\mid-2,16$ & $-2,24$ & $-1,05$ & \begin{tabular}{|l|}
0,99 \\
\end{tabular} & 0,75 & $-2,16$ & 1,39 \\
\hline 2010 & 2,24 & 0,86 & 0,44 & \begin{tabular}{|l|}
0,04 \\
\end{tabular} & $-2,30$ & $\mid-2,49$ & $-1,86$ & $\mid-2,86$ & \begin{tabular}{|l|}
$-0,79$ \\
\end{tabular} & 0,37 & $-1,66$ & $-0,50$ \\
\hline & & & & & & Legend & & & & & & \\
\hline & & & Norm: & & va Extr & trema & & ca Extre & & & & \\
\hline & & & & Chu & va Sev & vera & & ca Seve & & & & \\
\hline & & & & Chu & va Mo & derada & & ca Mod & lerada & & & \\
\hline & & & & & IFI & & & & & & & \\
\hline
\end{tabular}

Os resultados obtidos através dos dois índices se mostraram satisfatórios para a área de estudo, sendo que a diferença observada entre os dois está dentro da faixa de classificação entre chuva fraca - normal e seca fraca, no qual o índice SPI demonstrou maior variação, já o índice RAI para a referida faixa se mostrou mais eficaz na representação do fenômeno pluvial estudado, já que o referido índice não trabalha com uma faixa de variação, e sim com um valor fixo para a faixa dos valores da classe normal. 


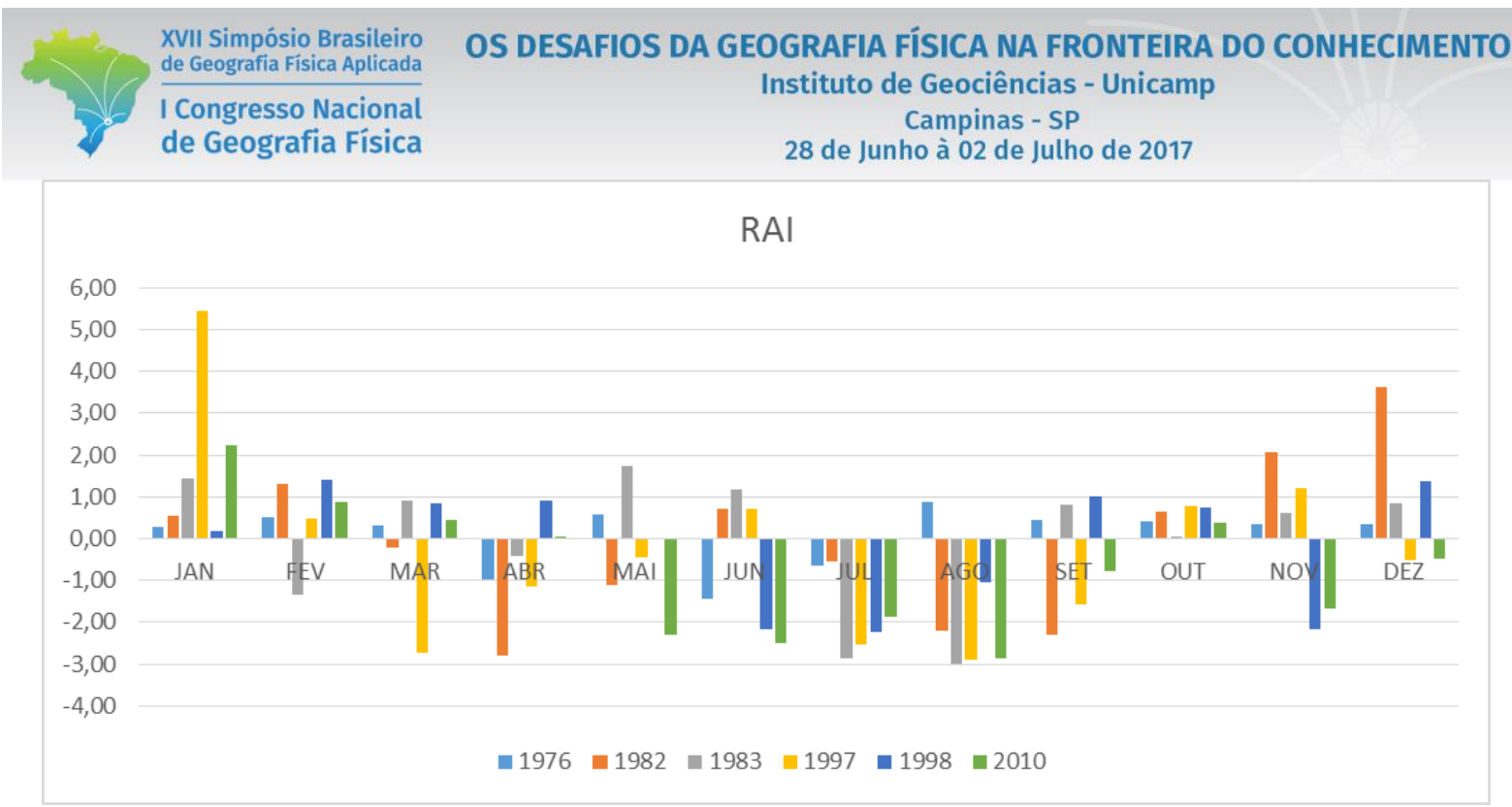

Figura 2 - Variabilidade do índice RAI na Bacia Hidrográfica Paraíba do Sul.

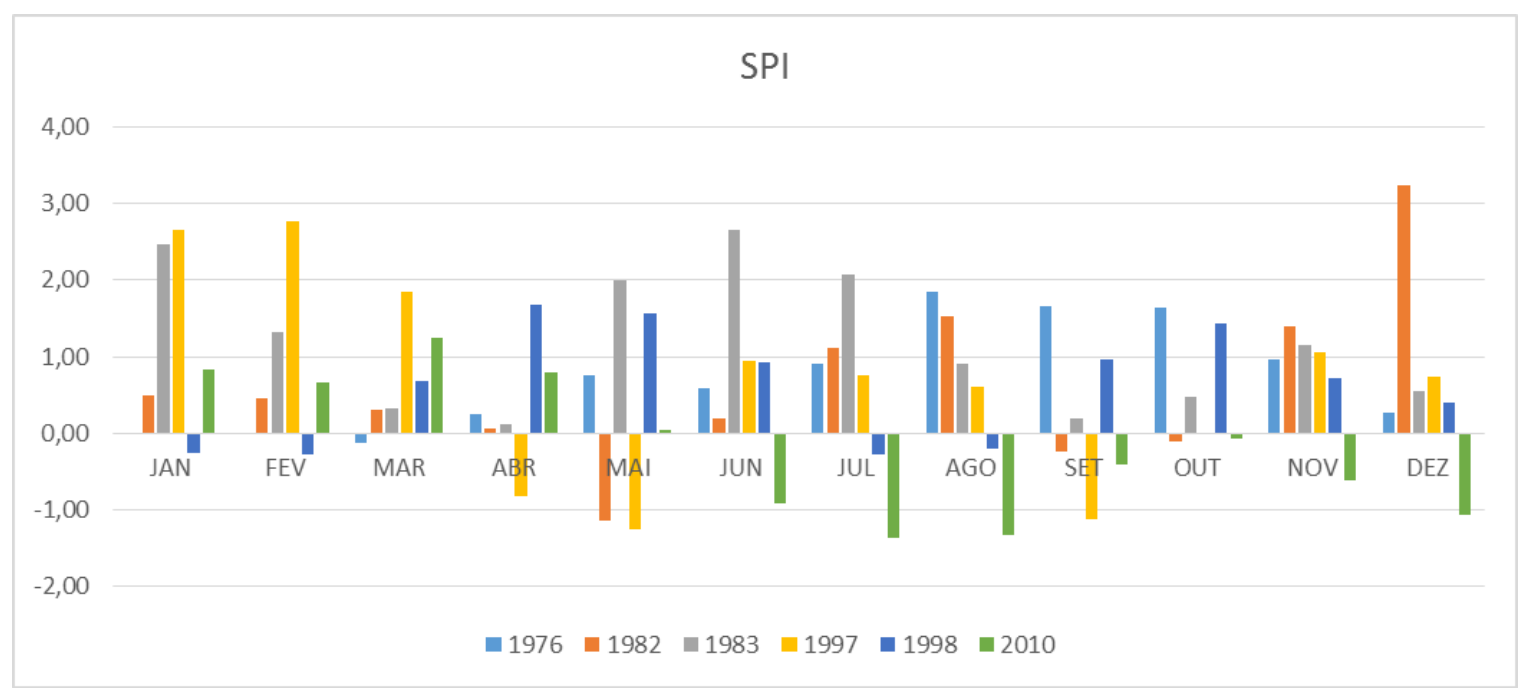

Figura 3 - Variabilidade do índice SPI na Bacia Hidrográfica Paraíba do Sul.

Em relação a classificação da área sobre os períodos de maior ou menor chuva pode ser observado nos gráficos a seguir como se comportou cada período em relação ao índice aplicado, sendo que para o índice SPI em relação ao RAI os valores de seca foram mais marcantes em relação ao outro índice, mas o índice RAI se comportou de forma mais próxima dos valores pluviométricos da área de estudo, sendo que os períodos de maior intensidade de chuva se concentraram nos meses de Janeiro a Março, com Janeiro sendo o período em toda a série a não apresentar nenhum registro de período de seca, já para os demais meses, Fevereiro registrou um ano de seca em 1983 e Março em 1997. Quanto aos períodos de seca, os meses de Abril até Agosto foram os meses considerados de muito pouca chuva na região, com variações de eventos 


\section{OS DESAFIOS DA GEOGRAFIA FÍSICA NA FRONTEIRA DO CONHECIMENTO \\ Instituto de Geociências - Unicamp \\ Campinas - SP \\ 28 de Junho à 02 de Julho de 2017}

de chuva nos meses Maio e Junho, cabe destacar que o mês de Junho foi o que apresentou um significativo índice de chuva para os anos de 1982, 1983 e 1997, sendo o único mês dentro do período considerado como de seca que se mostrou fora dos índices apresentados em relação aos outros meses. Em relação aos meses Setembro a Dezembro, os valores obtidos mostram os períodos de transição entre o período de estiagem para o chuvoso, no qual a alternância entre anos secos e chuvosos é mais marcante, em grande parte esta variação entre seco e chuvoso se deve ao início dos eventos de El Ninõ e La Ninã, que justamente neste período que tem uma maior influência sob as condições climáticas da área de estudo. Logo conclui-se que para a região da UGRHI-02, o índice RAI é o mais apropriado para descrever e ser utilizado no planejamento da gestão hídrica, pois mostrou-se mais eficaz e preciso na classificação dos períodos de seca e chuva para a referida região, como pode ser observado na Tabela III e conjunto de mapas anuais a seguir (Figuras 4 a 5), proporcionado uma melhor delimitação dos meses sob períodos de grande e pouca intensidade de chuva. Estes resultados colaboram para posteriores avaliações relacionadas a impactos em meio urbano principalmente, tais como inundações, processos erosivos e movimentos de massa em áreas de altas declividades e solos mais frágeis a ação a água. Em relação a distribuição espacial dos resultados obtidos através dos dois índices, os mesmos apresentaram maior concentração dos na região Nordeste da área de estudo, fator este que pode ser levado em consideração a proximidade desta área com regiões de altitudes elevadas e alta concentração, o que pode influenciar nos índices de precipitação desta área. 

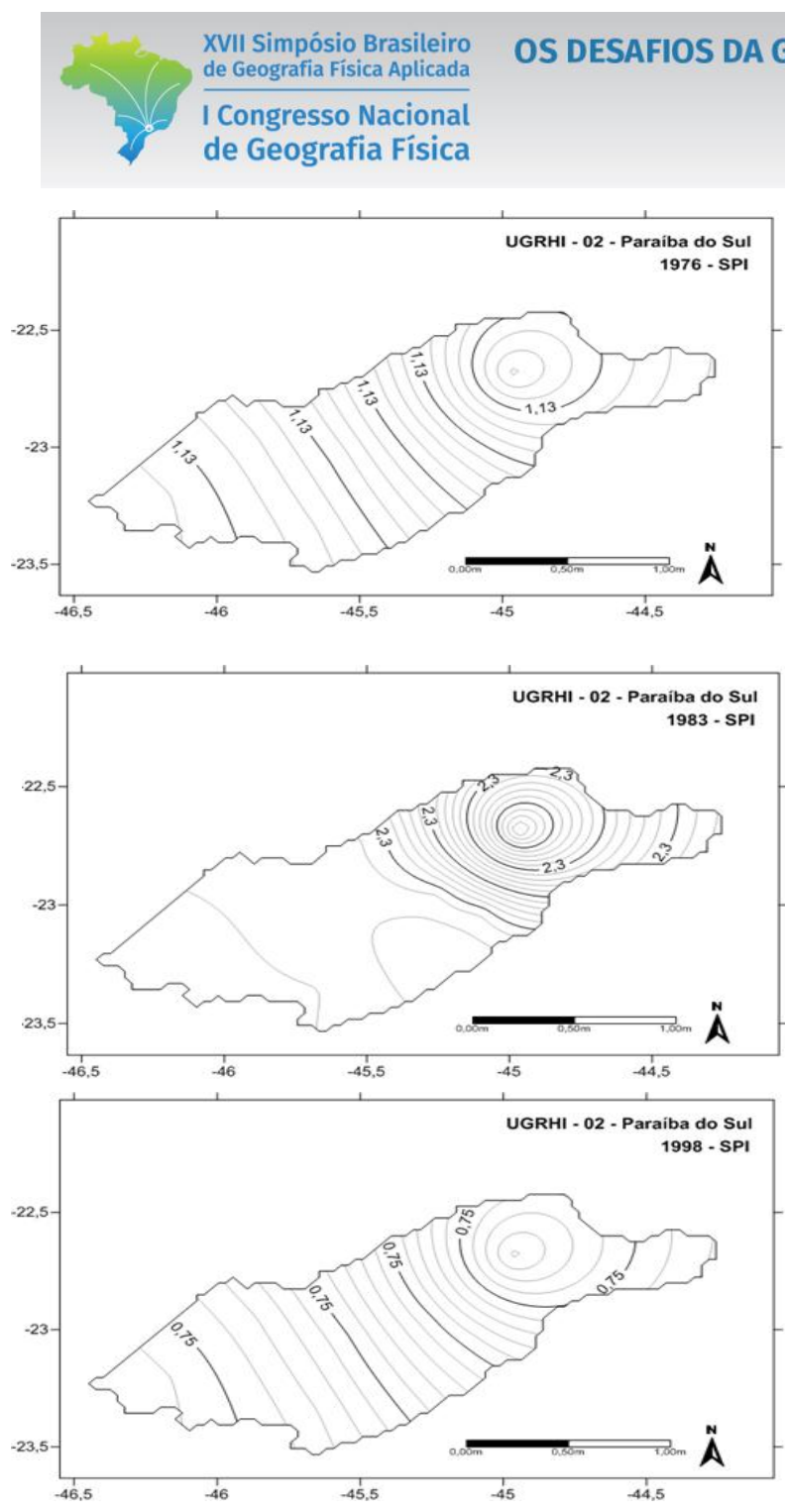
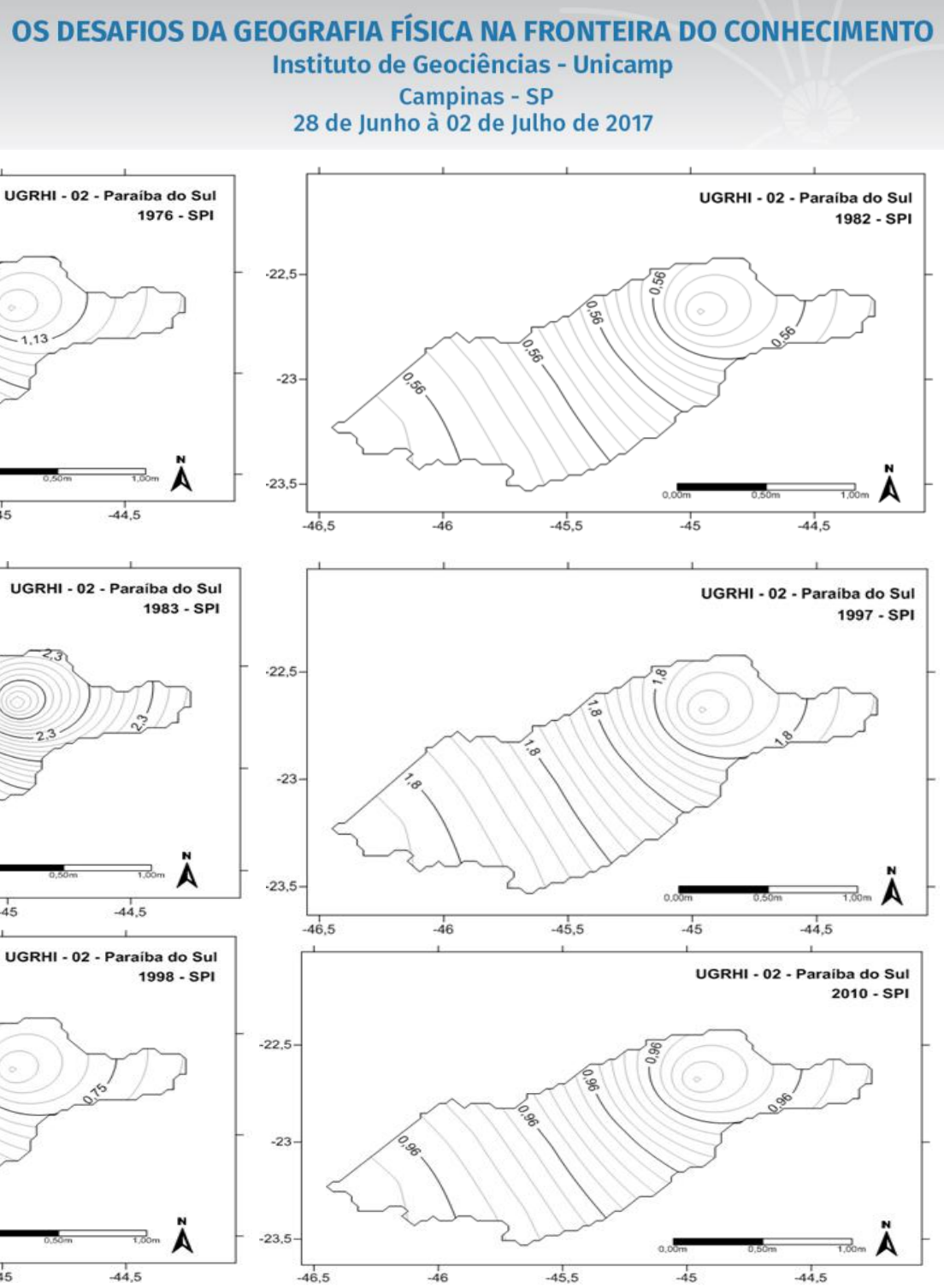

Figura 4 - Mapa Índice SPI (1976 a 2010). 

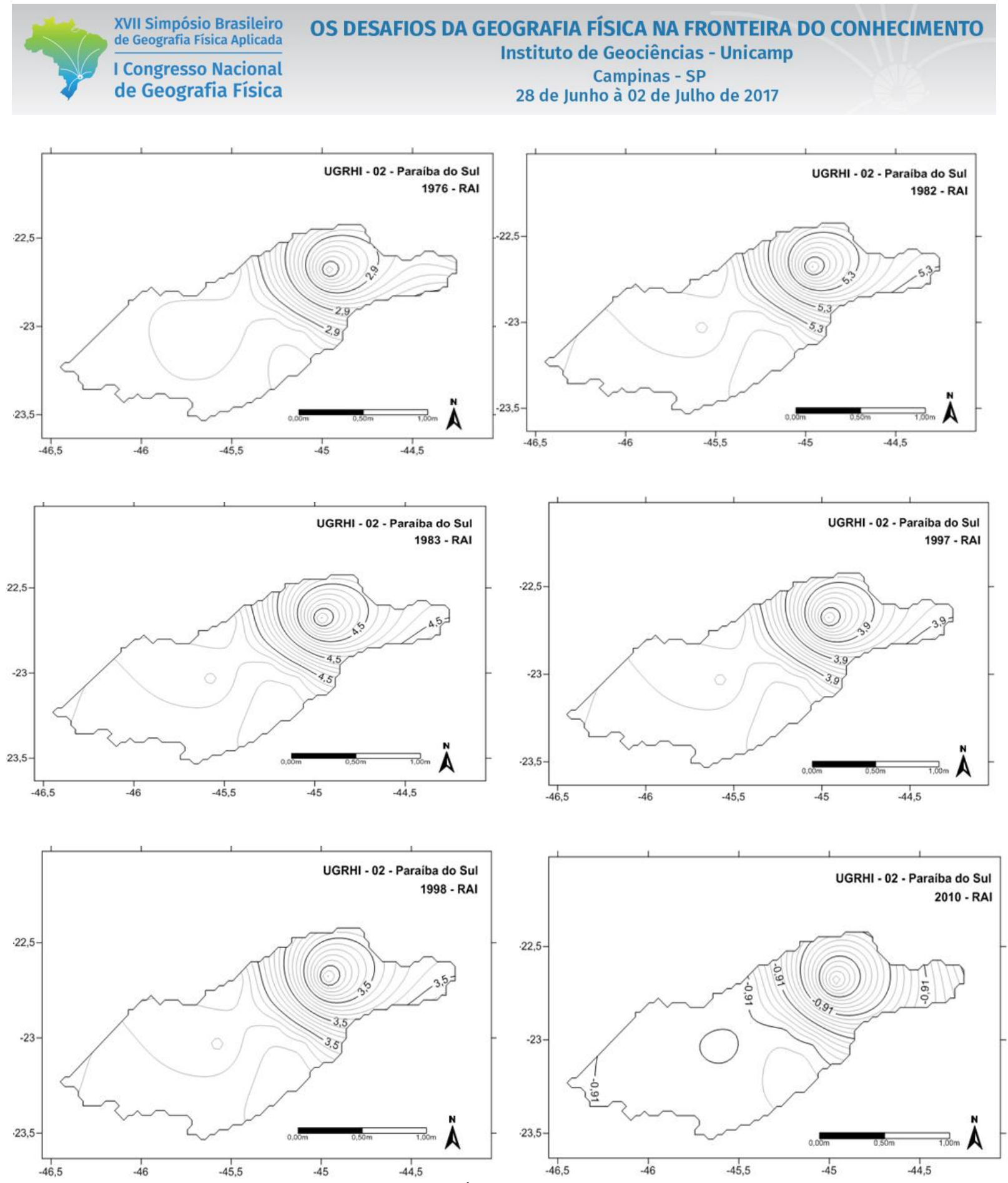

Figura 5 - Mapa Índice RAI (1976 a 2010).

\section{Considerações Finais}

O objetivo desta pesquisa foi analisar de forma quantitativa e espacial os resultados dos índices RAI e SPI aplicados na Unidade de Gerenciamento dos Recursos Hídricos-02 (Paraíba do Sul), considerando o período de 1976 a 2010, neste sentido, colocamos em destaque que o método de aplicação dos índices 


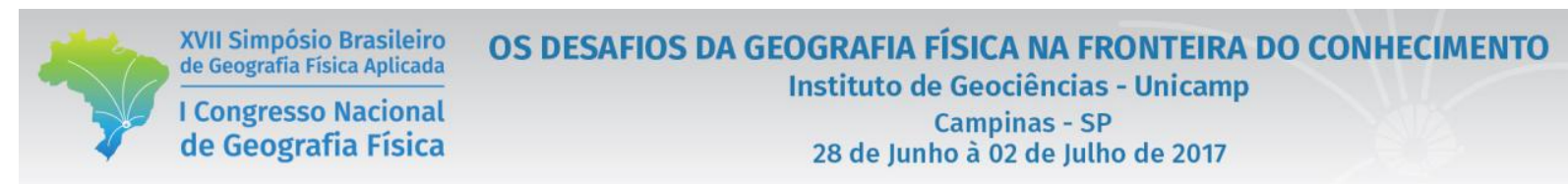

atendeu os objetivos inicias deste trabalho, permitindo verificar as ocorrências de períodos de chuva e seca na região. Estes resultados obtidos são de fundamental importância, pois fornecem informações para os estudos voltados as estiagens e para eventuais mitigações dos seus efeitos sobre a população inserida na referida UGRHI. Eventos extremos, como chuvas intensas podem desencadear diversos impactos, que em parte explicam o número crescente de desastres naturais, dentre os riscos expostos estão a ocorrência de inundações, deslizamentos, entre outros. Por outro lado a seca, também desencadeia diversos cenários de risco que tangem desde os riscos econômicos, sociais e ambientais. Como por exemplo, a diminuição da vazão dos rios impactua na capacidade de produção de energia, na produção agrícola e consequentemente na economia.

A partir das análises e avaliações dos resultados espaciais observou-se que a região Nordeste da área de estudo foi a que apresentou a maior amplitude em relação aos índices, tanto para os períodos de chuva como de seca, logo esta é uma área que merece grande atenção por parte do poder público com medidas a serem adotadas antes, durante e depois de ocorrências por eventos adversos de estiagem e alta pluviosidade.

\section{Agradecimentos}

Agradecemos à agência financiadora CAPES (bolsa de mestrado Demanda Social), tornando possível a submissão deste trabalho.

\section{Bibliografia}

AZEVEDO, P.V.; SILVA, V.P.R. Índice de seca para a microrregião do agreste da Borborema, no Estado da Paraíba. Revista Brasileira de Meteorologia, v. 9, n. 1, p. 66-72, 1994.

EWALD, K.H. Alterações do volume de precipitação no município de Marechal Cândido Rondon no período de 1965 a 2008. XVI Encontro Nacional de Geógrafos, Anais... Porto Alegre: 2010.

MARENGO, J.A e ALVES, L.M. Tendências Hidrológicas da Bacia do Rio Paraíba do Sul. INPE, v1 2005-05-12.

MOLION, L.C.B. Aquecimento Global, El Niños, Manchas Solares, Vulcões e Oscilação Decadal doo Pacífico. Revista Climanálise, ano 3, n.1, 2005.

REPELLI, C. A.; FERREIRA, N. S.; ALVES, J. M. B.; NOBRE, C. A. Índice de anomalia de precipitação para o Estado do Ceara. In: X Congresso Brasileiro de Meteorologia e VIII Congresso da FLISMET, Brasilia -DF, 1998.

ROOY, M.P. VAN. A Rainfall Anomaly Index Independent of Time and Space, Notes, 14, 43, 1965

SANCHES, F. O. Os Areais do sudoeste do Rio Grande do Sul: estudo sobre as chuvas no século XX e um possível cenário para o século XXI. Tese de Doutorado. Programa de Pós-Graduação em Geografia, Universidade Federal do Rio Grande do Sul. 2013. 188p.

THOM, H.C.S. Some Methods of Climatological Analysis - Technical Note nº 18, WMO nº 199, TP 103, 1966. 


\begin{tabular}{|c|c|}
\hline $\begin{array}{l}\text { XVII Simpósio Brasileiro } \\
\text { de Geografia Fisica Aplicada }\end{array}$ & $\begin{array}{l}\text { OS DESAFIOS DA GEOGRAFIA FÍSICA NA FRONTEIRA DO CONHECIMENTO } \\
\text { Instituto de Geociências - Unicamp }\end{array}$ \\
\hline $\begin{array}{l}\text { I Congresso Nacional } \\
\text { de Geografia Física }\end{array}$ & $\begin{array}{l}\text { Campinas - SP } \\
28 \text { de Junho à } 02 \text { de Julho de } 2017\end{array}$ \\
\hline
\end{tabular}

